\title{
PERCEPÇÃO DE IDOSAS A RESPEITO DO IMPACTO DA PARTICIPAÇÃO EM GRUPO DE CONVIVÊNCIA: ANÁLISE QUALITATIVA
}

Géssica Bordin Viera Schlemmer; UFRGS; gessicabordinviera@yahoo.com.br

Deise lop Tavares; UFSM; deiseiop@hotmail.com Juliana Duarte Ferreira da Costa; UFN; ju_dfc@hotmail.com Alecsandra Pinheiro Vendrusculo; UFN; alecsandrav@hotmail.com Melissa Medeiros Braz; UFSM; melissabraz@hotmail.com Alethéia Peters Bajotto; UFN; aletheia@bajotto.com.br

\section{RESUMO}

Introdução: $\mathrm{O}$ bem-estar no envelhecimento está relacionado à saúde física e à percepção de auto eficácia do idoso, ou seja, os cuidados com a sua saúde física, sendo assim, o objetivo desta pesquisa foi descrever e comparar pré e pós intervenção a percepção do impacto que o grupo de convivência apresenta na vida dos participantes. Métodos: Pesquisa qualitativa, através da análise de conteúdo de Bardin, por meio de pergunta aberta, as participantes foram questionadas: "O que este grupo representa para você?". A população deste estudo foi composta por idosas residentes na cidade de Santa Maria, RS, que iniciaram um protocolo de exercícios em meio aquático. O protocolo de pesquisa foi aprovado pelo CEP UFN nำ1.975.569. Resultados: Foram entrevistadas 21 idosas pré-intervenção e 11 pós-intervenção com média de idade \pm 68.09 anos. No primeiro momento, emergiram 4 categorias a partir de 22 inferências. São elas: Interação Social (10); Satisfação (7); Saúde/Doença (8) e Aspectos da Qualidade de Vida (8). No segundo momento emergiram 5 categorias a partir de 22 inferências. São elas: Interação Social (6); Satisfação (6); Saúde (6); Memória (3) e Coordenação Motora (1). Conclusão: a percepção do grupo na vida das idosas está intimamente relacionada à possibilidade de interação social, satisfação e saúde. Quando consideramos as diferenças da percepção pré e pós-intervenção, é oportuno frisar que estas, apontam a valorização da saúde em detrimento da doença. Ao deixar de considerar os aspectos da qualidade de vida, as idosas passaram a valorizar a aquisição de memória e melhora da coordenação motora.

Palavras-chave: Análise Qualitativa; Grupo de Convivência; Idoso. 